\section{Referenzmaterial, zertifiziertes}

C. Vidal ${ }^{1}$ und W.-R. Külpmann ${ }^{2}$

${ }^{1}$ Landeskriminalamt Niedersachsen, Dezernat 53 „Chemie“, Hannover, Deutschland

${ }^{2}$ Hannover, Deutschland

Englischer Begriff certified reference material; CRM

Definition Referenzmaterial mit Unterlagen, die von einer autorisierten Stelle herausgegeben wurden und das einen oder mehrere spezifizierte Merkmalswerte (s. $\triangleright$ Merkmal) mit beigeordneten Unsicherheiten und Rückführbarkeiten liefert, unter Anwendung gültiger Verfahren (Brinkmann 2012). Für Beispiel und Anmerkungen s. Literatur.

\section{Literatur}

Brinkmann B (2012) Internationales Wörterbuch der Metrologie (VIM) Deutsch-englische Fassung. ISO/IEC-Leitfaden 99:2007, 4. Aufl. Beuth-Verlag, Berlin 